\title{
O saber-realidade e a constituição docente: filosofando a Educação Matemática contemporânea
}

The know-reality and the constitution of teaching: philosophizing on contemporary mathematics education

\author{
Gilberto Silva dos Santos ${ }^{1}$ \\ Samuel Edmundo Lopez Bello²
}

\section{Resumo}

Neste artigo, temos como objetivo analisar as narrativas docentes a partir do que interpretamos como uso pedagógico da realidade na Educação Matemática. Os excertos selecionados de um congresso do campo referido foram organizados segundo suas semelhanças, possibilitando a constituição de identidades docentes que representam, controlam, regulam o uso pedagógico da realidade. Nosso viés teórico é pautado nos estudos de Michel Foucault a partir da perspectiva pósestrutural. Assim, atentos a essas representações, as produções da rede discursiva em Educação Matemática, buscamos tensionar como os discursos em torno da docência constituem um saber específico sobre a contemporaneidade. Não apenas constituem, mas são constituídos do que denominamos saber-realidade. Tal maneira de produzir a docência segue compondo os entendimentos; segue regulando e orientando as práticas pedagógicas em prol de uma matemática contextualizada, utilitarista, lúdica, significativa. Enfim, uma matemática que esteja em todos os lugares, que pertença a todos.

Palavras chave: Saber-realidade; Identidades docentes; Uso pedagógico da realidade; Práticas pedagógicas.

\section{Abstract}

In this article, we aim to analyze teacher narratives from what we interpret as pedagogical use of reality in Mathematics Education. The excerpts selected from a congress of the said field were organized according to their similarities, enabling the constitution of teaching identities that represent, control, and regulate the pedagogical use of reality. Our theoretical bias is based on the studies of Michel Foucault from the poststructural perspective. Thus, attentive to these representations, the productions of the discursive network in Mathematical Education, we try to stress how the discourses around the teaching constitute a specific knowledge about contemporaneity. They not only constitute, but are constituted of what we call know-reality. Such a way of producing teaching continues to compose the understandings; continues to regulate and guide pedagogical practices in favor of a contextualized, utilitarian, playful, meaningful mathematics. In short, a mathematics that is everywhere, belongs to everyone.

Keywords: know-reality. Teaching identities. Pedagogical use of reality. Pedagogical practices.

\footnotetext{
${ }^{1}$ Universidade Federal do Rio Grande do Sul | gilberto.santos@ufrgs.br

${ }^{2}$ Universidade Federal do Rio Grande do Sul | samuel.bello@ufrgs.br
} 


\section{A emergência das (com)posições}

As diversas produções em Educação Matemática - como livros, revistas, artigos, os cursos de formação inicial/continuada de professores, os documentos que normatizam os currículos escolares, as conversas entre professores - constituem uma rede discursiva. Tal discursividade produz efeitos. Antes de enxergarmos uma materialidade que esteja em algum lugar esperando ser descoberta, nós somos efeitos das redes discursivas que nos interpelam.

E é nessa rede que interpretamos o uso pedagógico da realidade como um saber sobre a docência que orientada, regulada, mas, igualmente, constitui e é constituído pelas práticas pedagógicas. Entendemos por uso pedagógico da realidade o campo discursivo que emerge dos saberes da etnomatemática e incita o docente a pensar suas práticas pedagógicas em função do uso da realidade. Não tratamos de uma realidade que comprova a existência da coisa em si ou de uma materialidade. Nossos estudos analisam como - discursivamente - nos assujeitamos a usar pedagogicamente a realidade. Tomamos a realidade na sua produção, pois, conforme Foucault (2007) quando falamos de alguma coisa, estamos constituindo-a.

Cientes da produção de um modo de saber contemporâneo, a partir da perspectiva pós-estruturalista, em especial, com os estudos do filósofo francês Michel Foucault, nos inclinamos para questionar os percursos, os movimentos, os esforços necessários para que as prescrições em torno do uso pedagógico da realidade atingissem esse lugar de saber e como tal, preenchessem um lugar de poder. Lugar isento de neutralidade, mas na medida que somos resultados de suas discursividades, aparamos os dispêndios necessários para que o uso que se faz da realidade na Educação Matemática apresente-se como algo universal, dado, estático. Em suma, como se os saberes fossem a-históricos.

Entendemos que as prescrições acerca das ações pedagógicas sobre o contextualizar, o observar a matemática em tudo, a realidade do aluno e o uso pedagógico da realidade na constituição docente produzem a materialidade da rede discursiva que nos propomos a analisar. É importante destacar que, com a filosofia foucaultiana, tanto o objeto quanto o sujeito passam a se constituir na medida em que se relacionam. Ou seja, o objeto só passa a existir no instante em que nos inclinamos a falar dele e, no mesmo percurso, constituímos nossa subjetividade à medida que, discursivamente, constituímos o objeto. Em resumo, as materialidades discursivas estão sempre em relação, imbricadas. O saber-realidade não estava na natureza à espera de nós como um objeto a ser observado. A partir dele, interpretamos, historicamente, as produções, os estudos, as pesquisas; os esforços, os saberes e poderes que se imbricam para que possamos, no contemporâneo, interpretar modos de ver e agir no/pelo saber-realidade.

Para Foucault (2012a), os discursos assujeitam, forjam, produzem, autorizam formas de pensar e de falar em detrimento a outras. Acreditamos que a partir de prescrições muito bem localizadas, os docentes vão se subjetivando ao uso pedagógico da realidade e narrando como suas as formas identitárias anunciadas na rede discursiva da Educação Matemática. Quando nos referimos a prescrições muito bem localizadas, estamos pensando os lugares de poder que o uso pedagógico da realidade ocupa para que possa emergir enquanto saber sobre a docência contemporânea. O saber-realidade emerge no campo da Educação Matemática a partir das produções etnomatemáticas. Num segundo instante, o saber-realidade apresenta-se como modo de constituir as práticas pedagógicas nos currículos escolares voltados à Educação Matemática (SANTOS, 2016). Ou seja, se há um primeiro momento em que o uso pedagógico da realidade apresenta-se enquanto 
produção, sendo cunhado por pesquisas no campo referido, no instante seguinte, ele passa a ser ofertado nos/pelos currículos escolares através dos documentos oficiais contemporâneos como os Parâmetros Curriculares Nacionais ( $P C N^{\prime}$ 's) entre outros. Sua presença em documentos produzidos pelo Ministério da Educação ou pela Secretaria Estadual de Educação do Rio Grande do Sul (SEDUC/RS) evidenciam o lugar de poder que o uso pedagógico da realidade ocupa.

Com isso, este artigo pretende analisar as narrativas de professores de matemática na tentativa de dar visibilidade às identidades docentes prescritas através do uso pedagógico da realidade. Mas que identidades docentes seriam essas?

\begin{abstract}
Os problemas que estudei são os três problemas tradicionais. 1) Que relações mantemos com a verdade através do saber científico, quais são as nossas relações com esses "jogos de verdade" tão importantes na civilização, e nos quais somos simultaneamente sujeitos e objetos? 2) Que relações mantemos com os outros, através dessas estranhas estratégias e relações de poder? Por fim, 3) quais são as relações entre verdade, poder e si mesmo? (FOUCAULT, 2012b, p. 293)
\end{abstract}

Com Foucault, as relações entre verdade, poder e si mesmo serão tensionadas na análise do artigo destacando o imbricamento entre verdade, poder e si mesmo. O uso pedagógico da realidade adquiri status de verdade no campo da Educação Matemática e passa a ser interpretado como um saber na emergência da etnomatemática. Seu poder evidencia-se à medida que tal uso apresenta-se diluído pelos documentos oficiais que versam sobre as questões curriculares. Por fim - a analítica do artigo - o si mesmo aparece na ponta final quando os docentes, ao narrarem suas práticas pedagógicas, usam a realidade como um saber sobre o contemporâneo.

Gostaríamos de destacar que os instantes apontados anteriormente não se distanciam ou organizam-se de forma linear. Antes disso, se relacionam de tal maneira que a divisão feita é uma opção nossa em função não só da analítica que operamos, mas do modo como apresentamos a escrita.

Por fim, analisaremos de que maneira o saber-realidade prescreve e institucionaliza modos de ser e agir do professor de matemática. Destacando que ao falar sobre suas práticas pedagógicas, os educadores matemáticos assujeitam-se a identidades docentes. Mais do que isso, evidenciaremos que as narrativas docentes utilizam pedagogicamente a realidade (re)atualizando o saber-realidade. Não há cópia, mas efeitos, produções, modos de dizer e ver na vontade de usar pedagogicamente a realidade.

\title{
O que falam os docentes sobre suas práticas pedagógicas
}

[...] quanto não precisou antes tornar-se ele próprio [o homem] confiável, constante, necessário, também para si, na sua própria representação, para poder enfim, como faz quem promete, responder por si como porvir! (NIETZSCHE, 2009, p. 44).

Analisar as identidades docentes é olhar para as formas como os professores representam suas práticas, bem como se constituem como sujeitos - em especial ao se inclinarem àquelas que se referem à Educação Matemática. A partir do uso pedagógico da realidade tanto na produção dos pesquisadores da área quanto nos documentos e nas políticas públicas voltadas à educação, os docentes vão se subjetivando e narrando suas 
identidades que, muitas vezes, se confundem com promessas num "responder por si como porvir", na vontade de trazer para si a identidade docente desejada em seu tempo. Desse movimento criam-se dualismos entre a identidade professor que se quer e a que não se quer. Enquanto a primeira é aceita e validada (re)atualizada pelo uso pedagógico da realidade, a segunda acaba sendo marginalizada, esquecida, escondida, mas também produzida pelo mesmo uso, pois ao incitar uma identidade como forma aceita do professor ela vai fixando, prescrevendo, constituindo, idealizando essa identidade e não outra.

O exercício analítico de apontar as identidades docentes tem como objeto de estudo os anais do X e do XI Encontro Gaúcho de Educação Matemática (EGEM), realizados, respectivamente, em 2009 e 2012. A escolha do EGEM emergiu a partir de pesquisas anteriores em que analisamos documentos de caráter nacional e regional (SANTOS, 2016). Desse estudo, surgiu à necessidade de tensionar como os docentes estão narrando suas práticas pedagógicas. Assim, este artigo se constitui a partir de excertos dos anais do EGEM que versam sobre o contextualizar, o trabalhar com o cotidiano, com toda a produção que denominamos de saber-realidade. Durante o desenvolvimento da análise dos excertos selecionados, percebemos semelhanças, familiaridades e distanciamentos entre os fragmentos escolhidos. Através dessas semelhanças, elaboramos as seguintes categorias de identidades docentes: identidade docente utilitarista/contextualizadora; identidade docente lúdica; identidade docente tecnológica; identidade docente metodológica dividida em duas categorias: projetos e resolução de problemas.

O presente artigo é um recorte da pesquisa de mestrado desenvolvida pelo primeiro autor sob orientação do segundo autor (SANTOS, 2016), subdividida em três partes. No estudo referido, discutimos as emergências do campo etnomatemático para apontar a constituição do saber-realidade. Em seguida, nos dedicamos a analisar documentos oficiais contemporâneos desenvolvidos tanto pelo Ministério da Educação (MEC) quanto pela Secretaria Estadual da Educação do Estado do Rio Grande do Sul (SEDUC/RS) no âmbito da Educação Matemática para pensar como o saber-realidade era prescrito aos currículos escolares. A última parte, que compõe o presente artigo, é constituída pela análise feita nos anais do X e do XI EGEM, nos anos de 2009 e 2012. Como na segunda parte estudamos documentos regionais, para analisarmos sua operacionalidade, deveríamos pesquisar anais de eventos que pudessem referenciar os documentos escolhidos anteriormente e que dessem conta de apresentar narrativas docentes. Ao analisar as práticas pedagógicas apresentadas nos anais do EGEM, estivemos atentos aos usos, as prescrições, os saberes emergentes dos documentos oficiais que (re)atualizavam o uso pedagógico da realidade, tanto no escopo regional quanto no nacional.

Não utilizamos pesquisadores renomados no âmbito da formação de professores em Educação Matemática, pois queríamos analisar como os professores que estão na educação básica fazem uso do saber-realidade. Em resumo, como o saber-realidade interpela o professor que está na escola; que lê; que tensiona; que discute; que nega; que aplica; que rasga os documentos oficiais. Não nos preocupamos em dizer se o uso feito é melhor ou pior que de outros pesquisadores (em suma, não atribuímos valorações ao saber-realidade), mas problematizamos como os usos pedagógicos da realidade deslocam-se das pesquisas em Educação Matemática e chegam aos currículos, à escola básica. Esse é o nosso percurso analítico. Como em qualquer percurso, há a necessidade de se fazer escolhas!

O que nos instiga a problematizar o saber-realidade é como esses saberes vão se atualizando de tal forma que acabam por se constituírem enquanto verdadeiros, compondo formas aceitas de ser docente. Em especial, acreditamos que essas inúmeras repetições das prescrições, dos saberes produzem normas que representam identidades docências. 0 
saber-realidade vem anunciar que isso precisou de tempo, investimento, para que ele ocupasse o lugar de saber e pudesse - com tanta convicção - instituir maneiras de ser e agir, pois "[...] as imagens que o mundo, principalmente social, apresenta, a rigor, ele não apresenta isentamente, isto é, é o olhar que botamos sobre as coisas que, de certa maneira, as constitui" (VEIGA-NETO, 2007, p. 30).

\section{Identidade docente}

Conforme os Parâmetros Curriculares Nacionais do Ensino Fundamental (PCNEF), a Matemática é uma ciência viva, caracterizada como "[...] uma forma de compreender e atuar no mundo" (DESSBESEL, CURY, 2012, p. 117)

Dos documentos à escola. Da escola ao docente. O percurso está dado, mas os usos, as maneiras que podem convocá-lo a pensar sua docência não. Há, ainda, o retorno: e ao voltarem ao discurso de prescrever, de legitimar, o que dizem as formas de ser docente? Ao utilizar os PCNEF, as autoras conduzem suas formas de pensar a matemática através das normatividades anunciadas pelos documentos. Assim, se os convites foram feitos, se as prescrições forem apresentadas (SANTOS, 2016), aqui surgem às maneiras pelas quais os docentes não apenas se percebem, mas tentam narrar o que (a)creditam - ou esperam - ser.

Conforme os Parâmetros Curriculares Nacionais [do] Ensino Médio (PCNEM), a Matemática tem o papel de contribuir com o desenvolvimento do pensamento, ou seja, desenvolver a capacidade de resolver problemas e, também servir como uma ferramenta que auxilia em quase toda a atividade humana (DESSBESEL, CURY, 2012, p. 118).

A constituição, o poder e o que pode ser dito são legitimados pelos documentos. Enxergar o papel da matemática "como ferramenta que auxilia em quase toda a atividade humana" não é apenas um convite feito pelo documento, mas a afirmação, a vontade de se constituir docente de acordo com as prescrições, as orientações vigentes.

Se a rede discursiva da Educação Matemática produz efeitos de verdade, então tais efeitos vão normatizando as maneiras de pensar a docência. Não estamos afirmando que tais formas não sejam adequadas em relação a outras ou vice-versa. $O$ que problematizamos é o movimento feito pelos docentes a partir do uso pedagógico da realidade. Mais do que isso, apontamos para como o saber-realidade perpassa a rede discursiva da Educação Matemática produzindo as maneiras, as formas como nós educadores matemáticos - nos narramos, nos assujeitamos à vontade de usar pedagogicamente a realidade.

Os dois excertos anteriores, evidenciam o uso que os docentes fazem das prescrições anunciadas pelos documentos curriculares. Percebemos as inclinações dos professores em relação aos documentos: os seus modos, as suas representações sobre o que é a matemática, como ela pode ser desenvolvida, bem como os modos de valorar as práticas pedagógicas. Não obstante, como os docentes elaboram - discursivamente- o objeto de desejo da docência contemporânea: o uso pedagógico da realidade.

Cabe destacar que não interpretamos uma verticalidade entre o que os documentos oficiais ofertam e aquilo que chega até as escolas. Não sejamos ingênuos! O desafio é apontar como aquilo que está sendo produzido nas pesquisas, nos documentos oficiais e 
nas narrativas docentes constituem uma rede, um emaranhado que produzem efeitos específicos. Nós, enquanto sujeitos (e, especificamente, enquanto educadores matemáticos), somos efeitos desses enunciados. Quando utilizamos os documentos oficiais, as prescrições, não repetimos - naturalmente - um enunciado, mas nos tornamos resultado, produto de suas articulações. Não há neutralidade em dizer aquilo que o documento, a etnomatemática diz; ao falar do documento, ao falar da etnomatemática, produzimos o que entendemos pelos documentos, pela etnomatemática. No mesmo percurso, nos produzimos, nos tornamos efeito desses discursos, pois ao falarmos deles, também falamos de nós. Ao falarmos de nós, produzimos identidades docentes que emergem no percurso de usar pedagogicamente a realidade.

Conforme VEIGA-NETO (2007, p. 24), "[...] dou-me por satisfeito se puder contribuir para que cada professor e cada professora não aceite automática e silenciosamente, de modo não problemático, as grandes declarações [...]" que os inclinam a pensar, a produzir suas docências. Enfim, que as promessas que surgem como efeitos de verdades sejam tensionadas para que não se instaure uma docência mesmice em que todos se subjetivem a mesma representação docente.

O professor tem o papel de estimular e desenvolver habilidades, assim como preparar o aluno para sua realidade. Para efetivar esta tarefa, o professor deverá mudar sua visão com relação ao Ensino da Matemática, de maneira que, torne o aluno como centro do processo educacional e enfatize o processo de construção do conhecimento (LAZZARDI, LIMA, SCHULZ, 2012, p.661).

O alerta para mudar as ações docentes é lançado. Cabe ao professor escolher, optar por estratégias que agregam as suas práticas o uso pedagógico da realidade. Assim,

[...] o discurso pedagógico [como] um dos norteadores para produzir formas de ser docente entre os professores. Dessa forma, nosso estudo busca percorrer alguns discursos em educação matemática que evidenciam formas de ser docente assim como, os usos e seus significados na constituição das práticas em educação matemática possibilitando a produção de verdades (SANTOS, SANTOS, 2014, p. 2).

As produções de verdades vão se apresentando à medida que os docentes vão convocando novos professores a pensar suas ações pedagógicas. Se o saber-realidade é produzido e instituído como a forma prescrita para o docente contemporâneo, então seus efeitos incitam modos de pensar a docência e, uma vez que tais materiais assumem um lugar de verdade, produzem representações das identidades docentes.

[...] devem ser trabalhadas atividades que despertem o interesse e a motivação dos alunos, permitindo uma interação entre professor, aluno e saber matemático e possibilitando a busca de significações dos conceitos a serem construídos (SELVA, CAMARGO, 2009, p. 1).

A vontade por buscar significado, por encontrar e apresentar os lugares por onde a matemática anda e está presente vão constituindo formas de pensar a docência. Com isso, vão sendo representadas maneiras, condutas, normas que o docente precisa seguir para constituir suas práticas pedagógicas. Uma identidade docente produzida pelo uso pedagógico da realidade dá conta de convocar o docente a produzir significados auxiliando nas mais diversas atividades humanas. Denominamos essa categoria de identidade docente utilitarista/contextualizadora. 
É interessante pensar que cada uso, cada leitura feita dos documentos oficiais colocam em operação os valores da docência contemporânea. Os pesos da docência vão tendendo para o uso pedagógico da realidade, mas não apenas o uso, mas sim o bom uso do saberrealidade. Ao que nos parece, ser docente no contemporâneo implica aceitar e saber usar pedagogicamente a realidade ao passo que, caso o docente não saiba utilizar, contextualizar a matemática, acaba sendo rotulado, regulado pelo adjetivo ruim. Não enxergar a matemática em todos os lugares, em todos os contextos torna-se culpa do próprio professor e não uma prescrição documentada, elaborada nas tramas da Educação Matemática.

Com o intuito de contextualizar os conteúdos matemáticos e resgatar os diversos alunos que veem a Matemática como uma disciplina complexa e sem aplicação, utilizamos a sala de aula como um ambiente de Modelagem, com o intuito de aproximar alguns conteúdos matemáticos à realidade dos alunos, fazendo-os refletir e posicionar-se diante dos problemas apresentados (GOMES, VARGAS, 2012, p. 363).

A vontade de contextualizar como medida para uma boa prática pedagógica. Os discursos, em Foucault, perpassam os entendimentos linguísticos. Para ele, o discurso refere-se ao estudo das práticas sociais. É pertinente pensar que "a suposição, por exemplo, de que os discursos pedagógicos e alguns outros fabricam determinados tipos de práticas e estas, enquanto práticas sociais produzam subjetivações, identidades, regras institucionais, assujeitamentos "[...] nos incitam a tratar a prática pedagógica como prática discursiva" (BELLO, 2010, p. 564). "Os discursos da inovação curricular, da educação matemática contextualizada, das verdades da matemática escolar e, ainda, das verdades da experiência escolar dos sujeitos são os que constituem essas práticas" (BELLO, 2010, p. 565).

Percebe-se que a contextualização quer retirar a matemática da aula - por alguns minutos - para apresentá-la a vida, reforçando o utilitarismo de uma matemática usual que estaria em todos os lugares. Em contrapartida, temos a Modelagem Matemática metodologia de ensino que modela fenômenos naturais a partir da matemática aproximando os alunos de problemas de sua realidade. O que se constitui, discursivamente, como realidade - não apenas na Educação Matemática - é o desejo de enxergar a matemática em todos os lugares; de traduzir as vivências dos alunos; de reconhecer o que o outro faz, em que lugar ele vive para produzir uma matemática que esteja lá, que seja de todos.

Cabe ao educador adaptar as atividades, viabilizando desta forma as aprendizagens de conteúdos matemáticos muitas vezes considerados sem significado (PERES, MENEGAZZI, 2012, p. 231).

E ao educador, é lançado o desafio de procurar significados nas discussões matemáticas que compõem sua ação pedagógica. Mais uma vez, à vontade, o pedido para que as aulas de matemática não sejam meras reproduções de conteúdos e listagens extensas de atividades, mas formas de pensar/enxergar a matemática pelo mundo. Esse movimento legitima-se adquirindo lugar de verdade instituindo o saber-realidade na Educação Matemática não apenas sobre as condutas que devem ser seguidas, mas também pelas quais os docentes precisam se afastar.

[...] é importante que sejam pensadas atividades que integrem a matemática ao mundo real, de modo que o aluno perceba que existem relações entre a matemática ensinada na escola e a matemática da 
realidade, capacitando o educando a compreender e representar matematicamente essas relações (PEREIRA; NEHRING, 2009, p. 2).

O que nos instiga é como o efeito de verdade deixa de ser questionável e se advoga como verdadeiro por si sem apresentar suas lutas, suas batalhas e seus esforços para se (trans)formar em algo naturalizado. Uma vez que ela ocupa esse lugar, produz efeitos; produtos; instantes que vão desejar e inventar outras verdades. O dualismo da matemática mundo-escola vai afirmando-se na formação de um sujeito-professor utilitarista/contextualizador: aquele que procura o uso de cada conceito matemático no mundo. Podemos - inclusive- tomá-la como a identidade guarda-chuva do saber-realidade.

[...] queremos repensar a prática como o espaço de aprendizagem e de construção do pensamento prático do professor, permitindo e provocando o desenvolvimento de capacidades e competências sempre em diálogo com a situação real (BORJA et al, 2012, p. 441).

As valorações são feitas. E são tantas! No movimento de (re)pensar a prática, os docentes vão se identificando com a forma legitimada de narrar sua docência. E, com isso, vão mais do que desejando, novamente prescrevendo, já as suas interpretações, sobre o uso pedagógico da realidade, sobre essa forma-sujeito-professor de pensar sua prática no âmbito do real, do verdadeiro.

As redes sobre como pensar a docência vão sendo apresentadas. Os modos de ser e agir do docente vão sendo mapeados, desenhados, costurados em torno do significativo, do concreto, do real, da realidade. O desejo por elaborar diversas metodologias que aproximem o discente do conhecimento estudado vai adquirindo espaço no intuito de constituir outras maneiras de ser e agir a partir das práticas pedagógicas de outros professores.

\section{Identidade docente lúdica}

À medida que surgem dificuldades no ensino ou na aprendizagem de conteúdos matemáticos, manifesta-se também a necessidade de propostas pedagógicas e recursos didáticos que auxiliem tanto os professores em sua prática docente quanto os alunos na construção de conhecimentos matemáticos. Neste contexto, apresentam-se os jogos matemáticos [...] (SELVA, CAMARGO, 2009, p. 3).

Jogo como forma lúdica de pensar a docência. Seria o sujeito-professor lúdico? Aqui se instaura um saber sobre a infância: que as crianças gostam de brincar e manipular materiais concretos. O entendimento de que ao brincar com jogos matemáticos, o estudante vai aprendendo de uma forma familiar acaba adquirindo efeito de verdade no campo educacional. Os estudos da psicologia vão reforçando, constituindo investimentos para que o lúdico, o concreto sejam elementos da aula de matemática. Não se assuste professor! Você vai conseguir! Pela realidade do aluno... Nesse percurso, surgem às novas - ou não tão novas - prescrições ensinando como ser um sujeito-professor-lúdico.

Gostaríamos de destacar que a identidade docente lúdica não é uma categoria exclusiva de nosso estudo. Ao analisar o portfólio de um curso de pedagogia, Santos (2009, p. 87) discute que

Algumas unidades que tentam dar sentido extralinguístico para a educação matemática e, dessa forma, produzem posições identitárias de "ser" professor no interior dessa rede discursiva, por exemplo: a ludicidade 
que visa um ensino prazeroso da matemática, ao prazer que, neste caso, dá um sentido para a matemática.

[...] procurei desenvolver atividades utilizando jogos e a exploração de materiais concretos, com o objetivo de tornar as aulas mais interessantes, atrativas, participativas e principalmente significativas para os educandos (CEOLIN; NEHRING, 2009, p.1).

O lúdico prescrito, narrado como uma forma de significar a aprendizagem em matemática. Ao tornar a aula significativa, o docente vai se confortando, acreditando que usar pedagogicamente a realidade ajude-o a constituir significados, sentidos, formas úteis de ensinar e aprender.

\section{Identidade docente tecnológica}

O currículo precisa, portanto, ser flexível para possibilitar a inserção de recursos tecnológicos no planejamento dos professores e maior significância ao discente, pois este terá a oportunidade de fazer com que o computador esteja presente no seu cotidiano escolar e poderá "enxergar" que essa máquina é, também, uma fonte de informação que, se bem utilizada e com apoio de um profissional, pode gerar conhecimento (NICARETTA, 2012, p. 170).

Desenhos sobre o currículo vão sendo constituídos. Os convites são feitos na tentativa de convocar pela proximidade. Porém, ao se dizer docente que trabalha com o uso pedagógico da realidade, o professor não está apenas convocando outros colegas, mas está inclinando-se ao discurso em voga. Ao se posicionar pela promoção da inserção das tecnologias no currículo e no ensino de matemática, o saber-realidade adquire força e circula no desejo de apresentar estratégias para que essas ferramentas sejam utilizadas e potencializadas na escola, pois o uso de recursos tecnológicos está imerso no contemporâneo.

O avanço da tecnologia e a abundância de informações estão diretamente conectados com os jovens de hoje. A cada dia, estes têm mais acesso a uma enorme quantidade de informações advindas dos jornais, revistas, noticiários e internet. Neste contexto está o ensino, em especial o ensino de Matemática e de Estatística, que tem o papel de auxiliar a interpretação da realidade (DESSBESEL, CURY, 2012, p. 117).

A rede discursiva da Educação Matemática vai fabricando os sujeitos docentes. Seus efeitos inofensivos - em especial, os que versam sobre o uso pedagógico da realidade arrastam os docentes para se constituírem, se identificarem. Num movimento de se enxergar sujeito de determinados lugares e vozes, para determinados "usos".

Assumimos diferentes posições de sujeito dos discursos que nos fabricam. Somos produto do discurso ou, ainda, seu efeito. Efeito inofensivo, diria eu, visto que produz modos de pensar, de ser e de dizer (SANTOS, 2009, p. 17).

As maneiras como o uso pedagógico da realidade é (re)ofertado pelos docentes versam sobre a tentativa de constituir uma docência valorada como boa, uma identidade docente em consonância com as prescrições, com os desejos convocados pela rede discursiva, instituindo modos de ser e agir. 
O saber-realidade e todos os seus elementos compostos pelas produções de pesquisadores, pelos documentos, pelos anais dos X e XI EGEM, pela rede discursiva da Educação Matemática apresentam a vontade de poder, o desejo de adquirir força, voz, visibilidade, pois "[...] os saberes se constituem com base em uma vontade de poder e acabam funcionando como correias transmissoras do próprio poder a que servem" (VEIGANETO, 2009, p. 117).

As narrativas a seguir, tratam das metodologias que podem ser utilizadas na vontade de usar pedagogicamente a realidade. Dessa maneira, numa categoria geral, poderíamos denominá-las de identidade docente metodológica que versa sobre a metodologia como maneira de ser um docente utilitarista, contextualizador, tecnológico e porque não lúdico? Assim, vamos dividir os excertos a seguir segundo as familiaridades metodológicas. Gostaríamos de destacar que, por exemplo, a identidade docente tecnológica pode usar uma das metodologias a seguir, pois uma categoria não exclui a outra. $\bigcirc$ que queremos destacar é a força, à vontade com que as metodologias narram formas de trabalhar com o uso pedagógico da realidade.

\section{Metodologia: projetos/resolução de problemas}

Os conteúdos em torno de projetos, como forma de desenvolver atividades de ensino e aprendizagem, favorecem a compreensão da multiplicidade de aspectos que compõem a realidade, uma vez que permite a articulação de contribuições de diversos campos de conhecimento (DREHER; SEIBERT 2009, p. 3).

Desenvolver uma prática por projetos não apenas convoca a contextualização, mas a interdisciplinarização. Constituindo, conforme os desejos das prescrições, que a matemática seja vista em todos os lugares; que dialogue com todas as áreas.

[...] pois os educandos foram instigados, bem como por si só sentiram-se desafiados a encontrar a melhor solução para a situação em discussão, a partir de seus conhecimentos prévios(MORAES; CURY, 2009, p.6).

Sendo instigados, os alunos vão se sentindo desafiados a resolver os problemas. Mas não é qualquer problema ou história matemática; apenas os da realidade, do seu contexto. O contextualizar, o interdisciplinar vai constituindo-se como efeito de verdade e como forma aceita de praticar a docência, pois dessa o discente começa a observar sentido em suas aprendizagens. O sentido - para nós - (re)afirma a vontade de uma matemática utilitarista. Aqui, parece que estamos retomando as discussões curriculares tradicionais (SILVA, 2014) pensando que só poderia estar no currículo aqueles saberes uteis para a constituição da sociedade.

Portanto é necessário que a escola, e também o professor na aula de matemática, instigue e dê espaço ao aluno para desenvolver sua capacidade de reflexão e de tentar relacionar o conteúdo de matemática com sua realidade fora da escola. Neste sentido percebo que problemas reais são uma estratégia importante para as aulas de matemática, pois em cada conteúdo podemos enfatizar um aspecto da vida e, assim, surpreender os alunos com atividades novas (SOPPELSA; MILANI, 2009, p. 3). 
Aqui, pedimos licença para usar uma pergunta que percorre as aulas de matemática: Professor, mas para que eu vou usar isso na vida? Observa-se que tal questionamento vem (re)afirmando uma prática docente: a do utilitarismo; a da contextualização. A prática docente vem prescrevendo que o professor enxergue sua disciplina, suas discussões pelo mundo. Dessa maneira, ele vai constituindo uma prática que busca algumas aproximações com as vivências do aluno, mas quando as discussões vão incluindo abstrações, os discentes solicitam a utilidade, tentando - desejando - que o docente (re)signifique sua prática, (re)faça esse exercício de procurar a matemática em todos os lugares.

Fala-se demasiadamente... Mas insiste-se em falar! Talvez, o calar já esteja sendo um efeito do falar - demasiadamente - sobre esse exercício, essa vontade, esse efeito, essa força de pensar a Educação Matemática no e pelo uso pedagógico da realidade. "E não somos traídos por tudo aquilo que achamos importante? É o que mostra onde colocamos nossos pesos e para que coisas não possuímos pesos" (NIETZSCHE, 2012, p. 109). E talvez, seja o instante de perguntar: como inventamos os pesos que - humano, demasiado humano - precisamos carregar ao ocupar a docência?

As correntes são fortes, prendem e seguram com tamanha potência que por uma fração de segundo, tendemos a esquecer das invenções, das repetições, das prescrições ditas, lidas, interpretadas, valoradas que constituem formas fixas, precisas, mas convidativas de pensar a docência. As narrativas docentes quase violentaram a escrita, a discussão ao passo de talvez apagar a vontade - nossa- de não estacionar. As análises anteriores compuseram um percurso para constituir um plano sobre o saber-realidade: a vontade, a identificação, a representação de formas docentes na e pela Educação Matemática.

\section{Os ecos do saber-realidade}

O que fazer com tudo isso agora? Respirar! Inspirar! (A)creditar! $O$ artigo trouxe discursos recorrentes sobre as formas contemporâneas de ser docente. Ao observar os anais dos X e XI EGEM, percebemos as convocações em prol do saber-realidade, através das narrativas que prescrevem o uso pedagógico da realidade.

A recorrência discursiva que incita o uso pedagógico da realidade é -insistentemente apresentada possibilitando que seu uso seja (re)afirmado e legitimado, assim como, constituindo formas aceitas de pensar a docência por essas recorrências. Ou seja, a existência da luta, o investimento para que o uso pedagógico da realidade ocupe o lugar de saber vai sendo esquecido à medida que o discurso vai (re)aparecendo e (re)apresentando formas de ser docente. Percebe-se que o entendimento pedagógico da realidade vai constituindo-se como a verdade de um lugar, dos alunos, de uma experiência, de uma vivência, de uma contextualização, de uma interdisciplinarização. No decorrer do artigo, discutimos algumas categorias docentes: identidade docente utilitarista/contextualizadora, identidade docente lúdica, identidade docente tecnológica, identidade docente metodológica.

A identidade docente utilitarista/contextualizadora narrou à vontade de contextualizar, de produzir uma matemática que seja útil para cada cidadão. Na representação de uma forma docente que busca, que procura a matemática em todos os lugares.

A identidade docente lúdica trouxe saberes da psicologia e da infância proporcionando o entendimento de que ao interagir com o jogo - ou com material lúdico - o estudante produzirá significado a sua aprendizagem. Assim, narrando à vontade de significar não apenas as aprendizagens, mas a matemática, (re)afirmando a identidade utilitarista. 
Por sua vez, a identidade docente tecnológica narrou às representações que convocam o uso das tecnologias como maneira de pensar a docência contemporânea. O uso pedagógico da realidade vai sendo elaborado na medida em que se institui o uso da tecnologia como ferramenta para aproximar, significar, produzir sentido às aprendizagens em matemática.

A identidade docente metodológica apontou para projetos e resolução de problemas como modos de usar pedagogicamente a realidade. Durante a análise dos excertos, percebemos a convocação - indireta - do uso da modelagem matemática como ferramentas para contextualizar, para significar as aprendizagens matemáticas.

Seja pela ciência, pela verdade, pelo cotidiano, pela resolução de problemas, pela história matemática, pela vida, por escolhas éticas, foram apresentadas, listadas e validadas formas que regulam, normatizam, representam os modos de ser docente no campo da Educação Matemática contemporânea. Além disso, essas formas vão constituindo entendimentos do que seja a matemática hoje: algo real, contextualizado, interdisciplinar, dinâmico, concreto, útil, que está em todos os lugares...

Se os discursos recorrentes convocaram e compuseram maneiras de ser docente, eles também alertaram para as maneiras pelas quais o docente não terá bons resultados. A prescrição não disse que existem formas inviáveis de ser docente, mas o aviso estava na ordem de se distanciar de ações pedagógicas que não versam sobre o uso pedagógico da realidade. Dessa perspectiva, vemos o caráter valorativo do saber-realidade, pois a maneira como são escolhidas, convocadas, avaliadas as práticas pedagógicas, formas boas e ruins são efetivadas na discursividade docente. Ou seja, os supostos efeitos de verdade vão intercambiando lugar para os bons modos de ser professor - e os péssimos também. Ao passo que o saber-realidade emerge não enquanto saber suprassumo, mas como instrumento, ferramenta para se atingir o ideário docente que usa pedagogicamente a realidade.

\begin{abstract}
O poder do discurso da Educação Matemática sobre as práticas da vida cotidiana pode muito bem ser fictício, mas seus efeitos de domínio são bem concretos. A Educação Matemática produz essa vontade de cidadania ao fornecer uma fantasia de domínio para o saber matemático, fazendo com que se deseje este discurso. Essa fantasia produz os efeitos da realização desse desejo e gera uma certeza de que pode fazer com que ele se torne realidade. $O$ poder proporcionado pela Educação Matemática é um poder de controle, é o "mais" que ela possibilita a quem pensa dentro de seus limites (BAMPI, 1999, p. 99-100, aspas da autora).
\end{abstract}

Desejar, prescrever, convocar: esses foram os anúncios que os anais dos X e XI EGEM trouxeram, denunciando que o saber-realidade está na ordem do discurso (FOUCAULT, 2012a) contemporâneo. Suas produções, invenções silenciam as avaliações necessárias para emergir a rede discursiva que valora o uso pedagógico da realidade. Enquanto a-histórica, ela - a realidade produzida discursivamente - inclusive sobre nova (re)leitura insiste em dizer algo para e sobre a docência. Insiste em identificar, representar maneiras de ser e agir aparando as arestas que evidenciam suas produções, seus rastros.

A matemática advoga para si um pertencimento a realidade. Deseja ser verdadeira, mas não deseja desconstituir seu papel de deusa do conhecimento: a verdadeira verdade. Tentamos, enfim, esquartejar essas deusas do saber-realidade para suspeitar dos universais que interpelam nossos modos de ser docente constituindo nossas práticas por esse movimento. Esquecemos de refletir, de problematizar esses espaços; esquecemos de voltar 
às produções iniciais. Simplesmente esquecemos... Até quando a matemática vai esquecer suas produções, suas rupturas, suas constituições em prol de uma vontade de verdade que modela, concretiza e fixa maneiras de entendê-la, de ser professor? Não apenas uma vontade de verdade, mas como esse discurso vai naturalizando-se ao passo que torna-se algo validado e, a partir daí, pesa, distribui status de práticas pedagógicas boas e/ou ruins. Através dessas formas fixas, vamos tentando sobreviver com o que ainda é possível constituir seja pelo saber-realidade, seja por essas formas tão perfeitas e ideais de serprofessor-qualquer-coisa.

Não obstante, acreditamos que o uso pedagógico da realidade entra na ordem de rebanho - pensando com Nietzsche - descrevendo um ideal ascético (NIETZSCHE, 2009), ou seja, desejando esse uso mais por pensá-la no coletivo, por ouvi-lo frequentemente do que por acreditar que as distintas formas de organização possam produzir e constituir outros modos de matematizar. Gostaríamos de destacar que os primeiros entendimentos acerca do saber-realidade não estão sendo tomados como verdadeiros. Apenas estamos apontando para os entendimentos diversos. Percebemos - no contemporâneo- que as práticas pedagógicas em torno do saber-realidade tomam esse conceito como algo pronto. Acreditamos que em função de sua recorrência, o saber-realidade institui efeitos de verdades -supostamente inquestionáveis - à Educação Matemática ao ocupar lugares privilegiados no escopo da docência contemporânea. São as identidades, as representações universais que foram problematizamos neste artigo para pensarmos quais os percursos pelos quais ainda nos inclinamos em prol da contextualização, de enxergar a matemática em todos os lugares.

Enquanto rebanho, ao sermos interpelados - a todo instante - por essas redes discursivas supostamente ingênuas e neutras, esquecemos que nos tornamos efeito daquilo que dizemos. Mais do que isso, nos tornamos resultado das nossas avaliações, daquilo que insistimos em seguir... 


\section{Referências}

BAMPI, Lisete Regina. O discurso da educação matemática: um sonho da razão. Dissertação (Mestrado) - Programa de Pós-Graduação em Educação, Universidade Federal do Rio Grande do Sul, Porto Alegre, 1999.

BELLO, Samuel Edmundo Lopez. Jogos de linguagem, práticas discursivas e produção de verdade: contribuições para a educação (matemática) contemporânea. In: Zetetiké Unicamp - v.18, p.545-588, 2010.

BORJA, Margarete Fátima, et al. Formação em serviço de professores do ensino fundamental: um estudo a partir da resolução de problemas matemáticos. In: XI Encontro Gaúcho de Educação Matemática. - Ed. Univates, Lajeado/RS, p. 432-442, 2012. Disponível em: < https://www.univates.br/media/egem/XI_EGEM.pdf> Acesso em 16 out. 2018.

CEOLIN, Taíse; NEHRING, Cátia Maria. A experiência de uma futura professora com alunos de $5^{a}$ série utilizando jogos matemáticos e materiais concretos. In: X Encontro Gaúcho de Educação Matemática. - Ed. UNIJUI, Ijui/RS, 2009. Disponível em: <http://www.projetos.unijui.edu.br/matematica/cd_egem/fscommand/RE/RE_04.pdf> Acesso em 16 out. 2018.

DESSBESEL, Renata da Silva; CURY, Helena Noronha. A estatística ensinada em escolas públicas de cruz alta: uma pesquisa com professores. In: XI Encontro Gaúcho de Educação Matemática. - Ed. Univates, Lajeado/RS, p. 116-126, 2012. Disponível em: < https://www.univates.br/media/egem/XI_EGEM.pdf> Acesso em 26 mai. 2015.

DREHER, Marusa da Rosa; SEIBERT, Tania Elisa. A matemática e o tema transversal "meio ambiente" através do método de projetos. In: X Encontro Gaúcho de Educação Matemática. - Ed. UNIUI, Ijui/RS, $2009 . \quad$ Disponível em: <http://www.projetos.unijui.edu.br/matematica/cd_egem/fscommand/CC/CC_29.pdf > Acesso em 16 out. 2018.

FOUCAULT, Michel. A ordem do discurso. Trad. Laura Fraga de Almeida Sampaio. - 22 ed. São Paulo: Edições Loyola, 2012a.

FOUCAULT, Michel. As palavras e as coisas. uma arqueologia das ciências humanas. Trad. Salma Tannus Muchail. - 9 ed. - São Paulo: Martins Fontes, 2007.

FOUCAULT, Michel. Verdade, poder e si mesmo. In: FOUCAULT, Michel. Ditos e escritos V: ética, sexualidade, política. Trad. Elisa Monteiro, Inês Autran Dourado Barbosa. - 3 ed. - Rio de Janeiro: Forense Universitária, 2012b.

GOMES, Kelly Amorim; VARGAS, Paulo Roberto Ribeiro. Ensino e aprendizagem de matemática financeira utilizando um ambiente de modelagem matemática: um estudo de caso na educação de jovens e adultos do ensino médio. In: XI Encontro Gaúcho de Educação Matemática. - Ed. Univates, Lajeado/RS, p. 362-369, 2012. Disponível em: < https://www.univates.br/media/egem/XI_EGEM.pdf> Acesso em 16 out. 2018.

LAZZARDI, Luana; LIMA, Marcos Pinheiro; SCHULZ, Julhane Alice Thomas. Resolução de problemas contextualizados por meio da investigação matemática. In: XI Encontro Gaúcho de Educação Matemática. - Ed. Univates, Lajeado/RS, p. 661-666, 2012. Disponível em: < https://www.univates.br/media/egem/XI_EGEM.pdf> Acesso em 16 out. 2018. 
MORAES, Daiana; CURY, Helena Noronha. Uma experiência de resolução de problemas com alunos de quinta série do ensino fundamental. In: X Encontro Gaúcho de Educação Matemática. - Ed. UNIUI, Ijui/RS, 2009. Disponível em: <http://www.projetos.unijui.edu.br/matematica/cd_egem/fscommand/RE/RE_03.pdf> Acesso em 16 out. 2018.

NICARETTA, Elisângela Isabel. A utilização das ferramentas tecnológicas no processo de ensino-aprendizagem. In: XI Encontro Gaúcho de Educação Matemática. - Ed. Univates, Lajeado/RS, $\quad$ p. 168-176, 2012. Disponível em: < https://www.univates.br/media/egem/XI_EGEM.pdf> Acesso em 16 out. 2018.

NIETZSCHE, Friedrich. A gaia ciência. Trad. Paulo César de Souza. 1. Ed. - São Paulo: Companhia das Letras, 2012.

NIETZSCHE, Friedrich. Genealogia da Moral. Trad. Paulo César de Souza. - São Paulo: Companhia das Letras, 2009.

PEREIRA, Juliane Sbaraine; NEHRING, Cátia Maria. Confronto com a realidade escolar: compreensão e significado a aprendizagem matemática. In: X Encontro Gaúcho de Educação Matemática. - Ed. UNIJUI, Ijui/RS, 2009. Disponível em: < http://www.projetos.unijui.edu.br/matematica/cd_egem/fscommand/RE/RE_06.pdf> Acesso em 16 out. 2018.

PEREZ, Evelize Martins Kruger; MENEGAZZI Marlene. As mídias e a educação matemática. In: XI Encontro Gaúcho de Educação Matemática. - Ed. Univates, Lajeado/RS, p. 229-234, 2012. Disponível em < https://www.univates.br/media/egem/XI_EGEM.pdf>. Acesso em 16 out. 2018.

SANTOS, Gilberto Silva dos; SANTOS, Suelen Assunção. Docências em educação matemática: composições estéticas... In: X ANPED SUL, Florianópolis, p. 1 - 21, 2014. Disponível em: <http://xanpedsul.faed.udesc.br/arq_pdf/2024-0.pdf>. Acesso em: 16/10/2018.

SANTOS, Gilberto Silva dos. Saber-realidade: das prescrições aos desejos de constituir docências na educação matemática contemporânea. Dissertação (mestrado) - Programa de Pós-Graduação em Educação em Ciências: Química da Vida e Saúde, Universidade Federal do Rio Grande do Sul, Porto Alegre, 2016.

SANTOS, Suelen Assunção. Experiências narradas no ciberespaço: um olhar para as formas de se pensar e ser professora que ensina matemática. Dissertação (mestrado) - Programa de Pós-Graduação em Educação, Universidade Federal do Rio Grande do Sul, Porto Alegre, 2009.

SELVA, Kelly Regina; CAMARGO, Mariza. O jogo matemático como recurso para a construção do conhecimento. In: X Encontro Gaúcho de Educação Matemática. - Ed. UNIJUI, Ijui/RS, 2009. Disponível em: <http://www.projetos.unijui.edu.br/matematica/cd_egem/fscommand/CC/CC_4.pdf> Acesso em 25 mai. 2015.

SILVA, Tomaz Tadeu da. Documentos de Identidade: uma introdução às teorias do currículo. - 3. Ed. - Belo Horizonte: Autêntica Editora, 2014.

SOPPELSA, Janete Jacinta Carrer; MILANI, Raquel. A matemática financeira como auxílio à reflexão sobre a compra de bens de consumo. In: X Encontro Gaúcho de Educação 
Matemática. Ed. UNIJUI, Ijui/RS, 2009. Disponível em: < http://www.projetos.unijui.edu.br/matematica/cd_egem/fscommand/RE/RE_13.pdf> Acesso em 26 mai. 2015.

VEIGA-NETO, Alfredo. Olhares. In: COSTA, Marisa Vorraber (org.). Caminhos Investigativos I: novos olhares na pesquisa em educação. 3 ed. Rio de Janeiro: Lamparina editora, 2007. 